Article

\title{
In Vitro Pharmacokinetic/Pharmacodynamic Modelling and Simulation of Amphotericin B against Candida auris
}

\author{
Unai Caballero $^{1}$, Elena Eraso ${ }^{2}{ }^{\circledR}$, Javier Pemán ${ }^{3,4}$, Guillermo Quindós ${ }^{2}{ }^{\circledR}$, Valvanera Vozmediano ${ }^{5}$, \\ Stephan Schmidt ${ }^{5}$ and Nerea Jauregizar ${ }^{1, *}$ (i) \\ 1 Department of Pharmacology, Faculty of Medicine and Nursing, University of the Basque \\ Country (UPV/EHU), 48940 Leioa, Spain; unai.caballero@ehu.eus \\ 2 Department of Immunology, Microbiology and Parasitology, Faculty of Medicine and Nursing, University of \\ the Basque Country (UPV/EHU), 48940 Leioa, Spain; elena.eraso@ehu.eus (E.E.); \\ guillermo.quindos@ehu.eus (G.Q.) \\ 3 Microbiology Department, Hospital Universitario y Politécnico de La Fe, 46026 Valencia, Spain; \\ javier.peman@gmail.com \\ 4 Severe Infection Research Group, Health Research Institute Hospital La Fe, 46026 Valencia, Spain \\ 5 Center for Pharmacometrics and Systems Pharmacology, Department of Pharmaceutics, College of Pharmacy, \\ University of Florida, Orlando, FL 32827, USA; valva@cop.ufl.edu (V.V.); SSchmidt@cop.ufl.edu (S.S.) \\ * Correspondence: nerea.jauregizar@ehu.eus
}

Citation: Caballero, U.; Eraso, E.; Pemán, J.; Quindós, G.; Vozmediano, V.; Schmidt, S.; Jauregizar, N. In Vitro Pharmacokinetic/Pharmacodynamic Modelling and Simulation of Amphotericin B against Candida auris. Pharmaceutics 2021, 13, 1767. https://doi.org/10.3390/ pharmaceutics13111767

Academic Editors: Jonás Samuel Pérez-Blanco and José Martínez Lanao

Received: 28 September 2021

Accepted: 18 October 2021

Published: 22 October 2021

Publisher's Note: MDPI stays neutral with regard to jurisdictional claims in published maps and institutional affiliations.

Copyright: (c) 2021 by the authors. Licensee MDPI, Basel, Switzerland. This article is an open access article distributed under the terms and conditions of the Creative Commons Attribution (CC BY) license (https:/ / creativecommons.org/licenses/by/ $4.0 /)$.

\begin{abstract}
The aims of this study were to characterize the antifungal activity of amphotericin B against Candida auris in a static in vitro system and to evaluate different dosing schedules and MIC scenarios by means of semi-mechanistic pharmacokinetic/pharmacodynamic (PK/PD) modelling and simulation. A two-compartment model consisting of a drug-susceptible and a drug-resistant subpopulation successfully characterized the time-kill data and a modified $\mathrm{E}_{\max }$ sigmoidal model best described the effect of the drug. The model incorporated growth rate constants for both subpopulations, a death rate constant and a transfer constant between both compartments. Additionally, the model included a parameter to account for the delay in growth in the absence or presence of the drug. Amphotericin $\mathrm{B}$ displayed a concentration-dependent fungicidal activity. The developed PK/PD model was able to characterize properly the antifungal activity of amphotericin B against $C$. auris. Finally, simulation analysis revealed that none of the simulated standard dosing scenarios of $0.6,1$ and $1.5 \mathrm{mg} / \mathrm{kg} /$ day over a week treatment showed successful activity against $C$. auris infection. Simulations also pointed out that an MIC of $1 \mathrm{mg} / \mathrm{L}$ would be linked to treatment failure for $C$. auris invasive infections and therefore, the resistance rate to amphotericin B may be higher than previously reported.
\end{abstract}

Keywords: Candida auris; PK/PD model; amphotericin B; time-kill curves

\section{Introduction}

Candida auris is a multidrug-resistant fungal pathogen that has emerged globally as a cause of different infections, such as severe cases of fungemia [1,2]. Candidemia due to this pathogen is associated with a high rate of mortality, especially in immunocompromised patients. Other risk factors for C. auris candidemia include previous exposure to antibiotics and underlying diseases such as diabetes, cardiovascular diseases or COVID-19 [3,4].

Additionally, the virulence and pathogenic capacity of $C$. auris and the decreased susceptibility to antifungal drugs is greatly worrying. Tentative epidemiological breakpoints for available antifungal drugs have recently been published. Those reports highlight that $C$. auris has high MIC values for polyenes, azoles, echinocandins and nucleoside analogues $[5,6]$. However, MIC related susceptibility categorization of $C$. auris isolates should be cautiously interpreted, since species-specific clinical breakpoints have not yet been defined [7]. C. auris is resistant to fluconazole and both intrinsic and acquired resistance has been reported $[5,8]$. Reduced susceptibility to the other azoles, including the newest isavuconazole, has also been described [8]. Echinocandins are the first line treatment to 
treat C. auris infections [9], but resistance to these drugs or therapeutic failures can emerge rapidly in C. auris [10].

Regarding amphotericin B, a wide range of MIC values has been reported, with resistance rates ranging from 0 to $30 \%$ using $1 \mathrm{mg} / \mathrm{L}$ as cut-off [7,11-15]. Recently, amphotericin $\mathrm{B}$ was described as the only in vitro fungicidal agent against $C$. auris, unlike echinocandins [16]. These facts, alongside with the fact that amphotericin B is the first alternative to echinocandins for $C$. auris infections $[17,18]$, make it an interesting drug whose activity against this pathogen needs to be studied in deep.

In the current worrying scenario of reduced effective treatments to deal with $C$. auris infections, in vitro studies that use time-kill (T-K) curve experiments and pharmacokinetic/pharmacodynamic (PK/PD) models to simulate different dosing schedules and activity profiles, offer an attractive tool to describe the observed antifungal activity and to predict the efficacy of the studied drugs. There are few PK/PD models from in vitro kinetic data developed for antifungal drugs and Candida: caspofungin and fluconazole against Candida albicans [19]; voriconazole against Candida spp. [20]; and recently, anidulafungin against Candida spp. [21]. However, despite the relevance of C. auris, PK/PD modelling of antifungal drugs for this emergent species is still lacking.

The aim of this study was to develop a semi-mechanistic PK/PD model for amphotericin B against $C$. auris that can (a) describe the in vitro T-K experiment of clinical isolates of $C$. auris exposed to amphotericin B and (b) simulate the expected T-K curves for different dosing regimens and MIC scenarios.

\section{Materials and Methods}

Six C. auris blood isolates from the outbreak in Hospital Universitario y Politécnico La Fe (Valencia, Spain) were included in this study [22]. The MIC, defined as the minimum concentration producing $\geq 90 \%$ growth reduction, was determined following EUCAST guidelines [23]. The MIC of amphotericin B for the six isolates was $1 \mathrm{mg} / \mathrm{L}$.

Amphotericin B was obtained from Sigma-Aldrich (Madrid, Spain) as a powder. Stock solutions were prepared with DMSO as solvent and stored at $-80{ }^{\circ} \mathrm{C}$ until use.

Static T-K curve experiments were carried out on flat-bottomed microtitre plates in RPMI medium (Sigma-Aldrich), with a final volume of $200 \mu \mathrm{L}$ per well at $37^{\circ} \mathrm{C}$ for $48 \mathrm{~h}$. C. auris blood isolates were grown at $37^{\circ} \mathrm{C}$ for $24 \mathrm{~h}$ prior to the start of the experiment to obtain fungal cultures in early logarithmic phase growth. Cells were suspended in sterile distilled water to achieve a starting inoculum size of $1-5 \times 10^{5}$ colony forming units (CFU)/ $\mathrm{mL}$ and added to the microtitre plate containing amphotericin $\mathrm{B}$ at concentrations $0.25,0.5,1,2$ and 4 times the MIC. Growth control was also measured by adding the inoculum to wells containing RPMI medium without amphotericin B. Sample for viable counts were taken at $0,2,4,6,8,24$ and $48 \mathrm{~h}$, plated in triplicate onto Sabouraud dextrose agar (SDA) and incubated for $24-48 \mathrm{~h}$ at $37^{\circ} \mathrm{C}$. Depending on drug concentration, samples were either first diluted in PBS or plated directly. When it was expected a sterilizing activity, the whole well was sampled onto an SDA plate. Experiments were performed in duplicate for each isolate on different days. The lower limit of detection was $5 \mathrm{CFU} / \mathrm{mL}$. However, due to the well-known sterilizing activity of amphotericin B, all the samples that showed no growth at all were considered to be $0 \mathrm{CFU} / \mathrm{mL}$. Carryover effect was determined as previously described [24].

The basis of the semi-mechanistic model included two fungal stages in the PD part of the model, consisting of a drug-susceptible fungal subpopulation (S) and a drug-resistant subpopulation (R) [25]. This two-subpopulation model accounted for the biphasic killing behaviour observed in the individual isolate static T-K curves (individual plots not shown).

First-rate order constants that defined both populations were the natural growth rate $\left(\mathrm{k}_{\text {growth }}\right)$, natural death rate $\left(\mathrm{k}_{\text {death }}\right)$ and the transfer constant from $\mathrm{S}$ into $\mathrm{R}\left(\mathrm{k}_{\mathrm{SR}}\right)$. The equation that described $S$ subpopulation in the absence of drug was as follows:

$$
\mathrm{dS} / \mathrm{dt}=\mathrm{k}_{\text {growthS }} \times \mathrm{S} \times\left(1-\mathrm{e}^{-\alpha \mathrm{t}}\right)-\mathrm{k}_{\text {death }} \times \mathrm{S}-\mathrm{k}_{\mathrm{SR}} \times \mathrm{S}
$$


where $\mathrm{dS} / \mathrm{dt}$ is the change in the number of the $\mathrm{S}$ subpopulation as a function of time.

It was not possible to perform a simultaneous estimation of both $\mathrm{k}_{\text {growths }}$ and $\mathrm{k}_{\text {death }}$ in this experimental setting. Hence, in an initial fit, $\mathrm{k}_{\text {growths }}$ was estimated by fitting a single-stage model [19] to the control data. Based on this estimation of $k_{\text {growth }}\left(0.118 \mathrm{~h}^{-1}\right)$ and on previous analysis, $\mathrm{k}_{\text {death }}$ was then fixed to $0.01 \mathrm{~h}^{-1}$ for final parameter estimation in the two-stage model. Parameter $\alpha$ accounted for the delay in growth observed due to experimental settings.

A specific $k_{\text {growth }}$ was estimated for the $\mathrm{R}$ subpopulation ( $\mathrm{k}_{\text {growthR }}$ ) to account for the regrowth observed at certain concentrations from 24 to $48 \mathrm{~h}$. The $\mathrm{k}_{\text {death }}$ parameter was negligible in the final equation describing $R$ subpopulation, hence it was not considered in the following equation:

$$
\mathrm{dR} / \mathrm{dt}=\mathrm{k}_{\text {growthR }} \times \mathrm{R}+\mathrm{k}_{\mathrm{SR}} \times \mathrm{S}
$$

As previously mentioned, $\mathrm{k}_{\mathrm{SR}}$ is the parameter that described the transfer of fungal cells from a susceptible state into a resistant one. It was defined as follows:

$$
\mathrm{k}_{\mathrm{SR}}=\frac{\left(\mathrm{k}_{\text {growth }}-\mathrm{k}_{\text {death }}\right) \times(\mathrm{S}+\mathrm{R})}{\mathrm{N}_{\max }}
$$

where $S$ and $R$ are the compartments with susceptible and resistant fungal populations, respectively, and $\mathrm{N}_{\max }$ is the maximum total density of fungal population in the stationary phase (in $\log \mathrm{CFU} / \mathrm{mL}$ ).

The effect of amphotericin B on the fungal killing of the susceptible subpopulation was modelled using an $\mathrm{E}_{\max }$ sigmoidal equation:

$$
\text { Drug effect }=\frac{E_{\max } \times C^{h}}{E C_{50}^{h}+C^{h}}
$$

where $\mathrm{E}_{\max }$ is the maximum achievable drug-induced fungal killing-rate constant, $\mathrm{EC}_{50}$ is the drug concentration necessary to achieve half the maximum effect, $\mathrm{C}$ is the drug concentration and $h$ is a Hill factor or sigmoidicity factor that modifies the steepness of the slope and smoothens the curve.

The final model for the $\mathrm{S}$ and $\mathrm{R}$ subpopulations were described according to Equations (2) and (5):

$$
\begin{gathered}
\mathrm{dS} / \mathrm{dt}=\mathrm{k}_{\text {growthS }} \times \mathrm{S} \times\left(1-\mathrm{e}^{-\alpha \mathrm{t}}\right)-\text { Drug effect } \times \mathrm{S}-\mathrm{k}_{\text {death }} \times \mathrm{S}-\mathrm{k}_{\mathrm{SR}} \times \mathrm{S} \\
\mathrm{dR} / \mathrm{dt}=\mathrm{k}_{\text {growthR }} \times \mathrm{R}+\mathrm{k}_{\mathrm{SR}} \times \mathrm{S}
\end{gathered}
$$

All T-K data were transformed into $\log \mathrm{CFU} / \mathrm{mL}$ and simultaneously analysed in NONMEM v7.4 with ADVAN13 subroutine and first-order conditional estimation method (FOCE). Residual variability was estimated by using an additive model. As six clinical isolates were analysed, inter-individual variability (IIV) was checked. Additionally, interoccasion variability (IOV) was also investigated to account for the variability that might have arisen either from each experimental day or from microtitre plate batch preparation. Model performance was assessed by precision of parameter estimates, changes in objective function value (OFV) and evaluation of diagnostic plots. Final model selection was also assisted by the performance of visual predictive checks (VPCs) and non-parametric bootstrap. VPCs were performed and graphically represented with NONMEM and S-PLUS software, stratified by concentration, with the experimental plots overlaid by the median and $95 \%$ prediction interval of a simulated virtual population of 1000 individuals. Non-parametric bootstrap was conducted by resampling 1000 datasets using Perl speaks NONMEM (PsN).

In vivo PK parameters for amphotericin $B$ deoxycholate were extracted from a tricompartmental model previously described in the literature, $\mathrm{V}_{1}=0.136 \mathrm{~L} / \mathrm{kg} ; \mathrm{V}_{2}=0.275 \mathrm{~L} / \mathrm{kg}$; $\mathrm{V}_{3}=1.4 \mathrm{~L} / \mathrm{kg} ; \mathrm{Cl}=0.013 \mathrm{~L} / \mathrm{h} / \mathrm{kg} ; \mathrm{Q}_{12}=0.35 \mathrm{~L} / \mathrm{h} / \mathrm{kg} ;$ and $\mathrm{Q}_{13}=0.026 \mathrm{~L} / \mathrm{h} / \mathrm{kg}$ [26]. The ef- 
fect of treatments with standard clinical doses of $0.6,1$ and $1.5 \mathrm{mg} / \mathrm{kg} /$ day were simulated for a virtual population of 1000 patients, considering free drug plasma concentrations for a typical unbound fraction of 0.045 [27]. Additional simulations were performed to test scenarios where amphotericin B MICs for C. auris were $0.06-0.5 \mathrm{mg} / \mathrm{L}$, according to the following equation [28]:

$$
\mathrm{MIC}=\left(\frac{\mathrm{d}}{\mathrm{E}_{\max }-\mathrm{d}}\right)^{1 / \mathrm{h}} \times \mathrm{EC}_{50}
$$

where $\mathrm{d}$ is a drug-independent constant and $\mathrm{h}$ is the Hill factor. The $\mathrm{EC}_{50}$ value for each MIC scenario was then included in the PK/PD model and simulations were performed similarly. All simulations were conducted with NONMEM and S-PLUS.

\section{Results}

\subsection{Time-Kill Experiments}

Graphical representation of mean T-K curves for all isolates and replicates is shown in Figure 1. No antifungal carryover was observed. Amphotericin B showed concentrationdependent fungicidal activity. Fungicidal effect ( $3 \mathrm{log}$ reduction compared to initial inoculum) was rapidly achieved, at 2 and $4 \mathrm{~h}$, for concentrations of $4 \mathrm{mg} / \mathrm{L}$ and $2 \mathrm{mg} / \mathrm{L}$, respectively. At concentrations of $1 \mathrm{mg} / \mathrm{mL}$ (equal to MIC), the effect was fungistatic overall, with a biphasic killing kinetic trend that showed fungal regrowth by the end of the experiment in some clinical isolates.

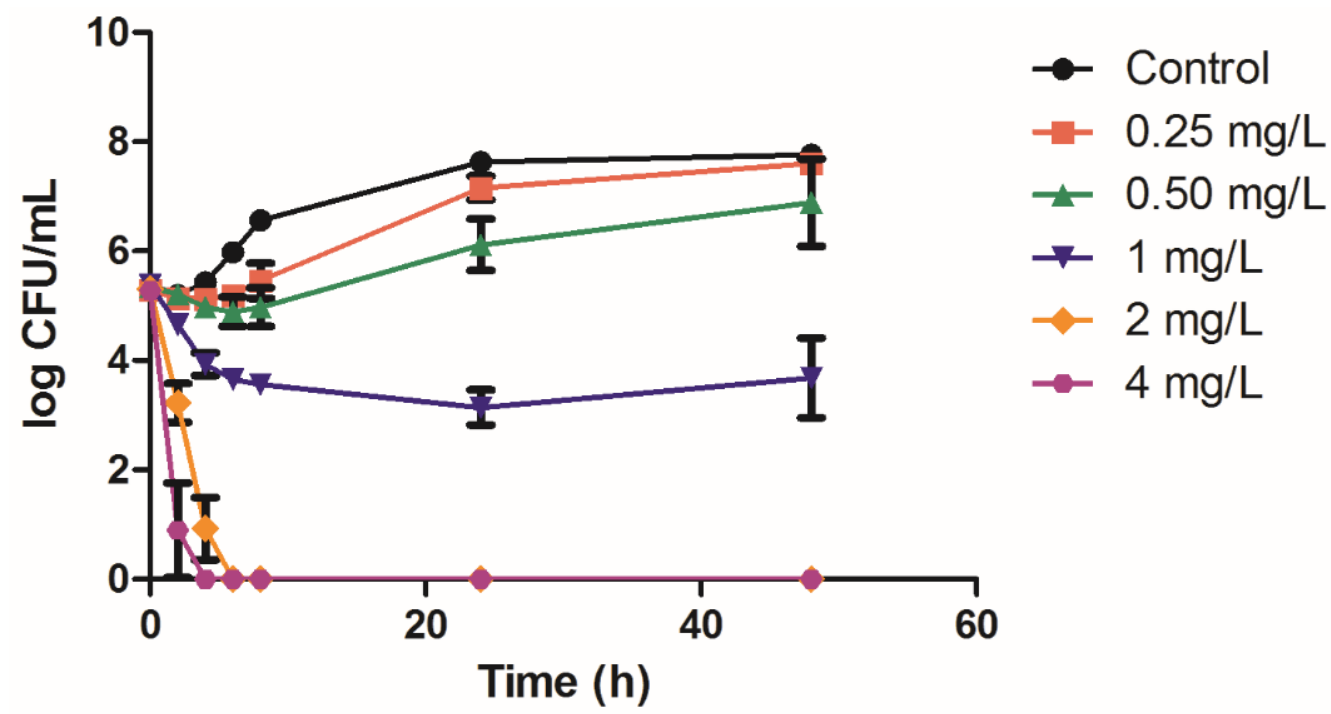

Figure 1. Mean time-kill curves for amphotericin B against C. auris. Each data point represents the mean result \pm standard deviation (error bars) of the six isolates and replicates.

\subsection{Semi-Mechanistic PK/PD Modelling}

The developed model was able to describe successfully the effect of amphotericin B against the studied C. auris clinical isolates. This model could characterize the initial and higher killing rate at the higher amphotericin B concentrations, 2 and $4 \mathrm{mg} / \mathrm{L}$, as well as the biphasic trend or regrowth observed in most experiments with the concentration of $1 \mathrm{mg} / \mathrm{L}$. A schematic illustration of the final model is shown in Scheme 1. 


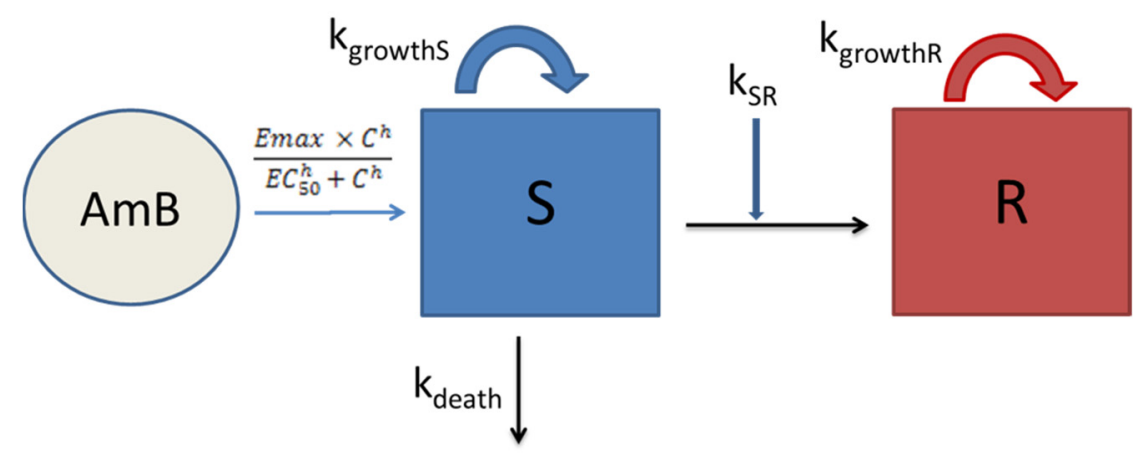

Scheme 1. Schematic illustration of the final PK/PD model. The total fungal population consists of two different subpopulations $(S+R)$, with a first-rate order constant $\left(k_{S R}\right)$ that describes the transfer of fungal cells from a susceptible state $(S)$ to a resistant one (R). Amphotericin B (AMB) exerts its effect on the susceptible subpopulation. $\mathrm{k}_{\text {growths: }}$ growth-rate of susceptible subpopulation; $\mathrm{k}_{\text {growthR: }}$ growth-rate of resistant subpopulation. $\mathrm{k}_{\text {death }}$ : death-rate constant of the susceptible subpopulation.

Final model parameters and the standard error of the estimates, alongside bootstrap estimations are presented in Table 1. Considering the standard errors and the bootstrap results, the parameters of the model were properly estimated. Candida related parameters were $\mathrm{k}_{\text {growthS }}$ and $\mathrm{k}_{\text {death }}$ for $\mathrm{S}$ subpopulation $\left(0.111 \mathrm{~h}^{-1}\right.$ and $0.01 \mathrm{~h}^{-1}$, respectively) and $\mathrm{k}_{\text {growthR }}$ for $\mathrm{R}$ subpopulation $\left(0.01 \mathrm{~h}^{-1}\right)$. $\mathrm{k}_{\text {death }}$ and $\mathrm{k}_{\text {growthR }}$ were fixed whereas $\mathrm{k}_{\text {growthS }}$ was allowed to be estimated. When the model incorporated different values of $\alpha$ (delay in growth) for the absence or presence of the drug, a better fit was achieved. A modified $E_{\max }$ sigmoidal model best described the effect of the drug; $E_{\max }$ was equal to $0.784 \mathrm{~h}^{-1}$ and $\mathrm{EC}_{50}$ was equal to $1.88 \mathrm{mg} / \mathrm{L}$ (1.88 times bigger than the MIC). Hill factor was fixed to enable a proper estimation of the PD parameters. Variability in the response was best captured by IOV on $\mathrm{EC}_{50}$ rather than IIV, where each occasion (four in total) was defined as each prepared batch of microtitre plates. Model appropriateness was supported by the VPCs depicted in Figure 2.
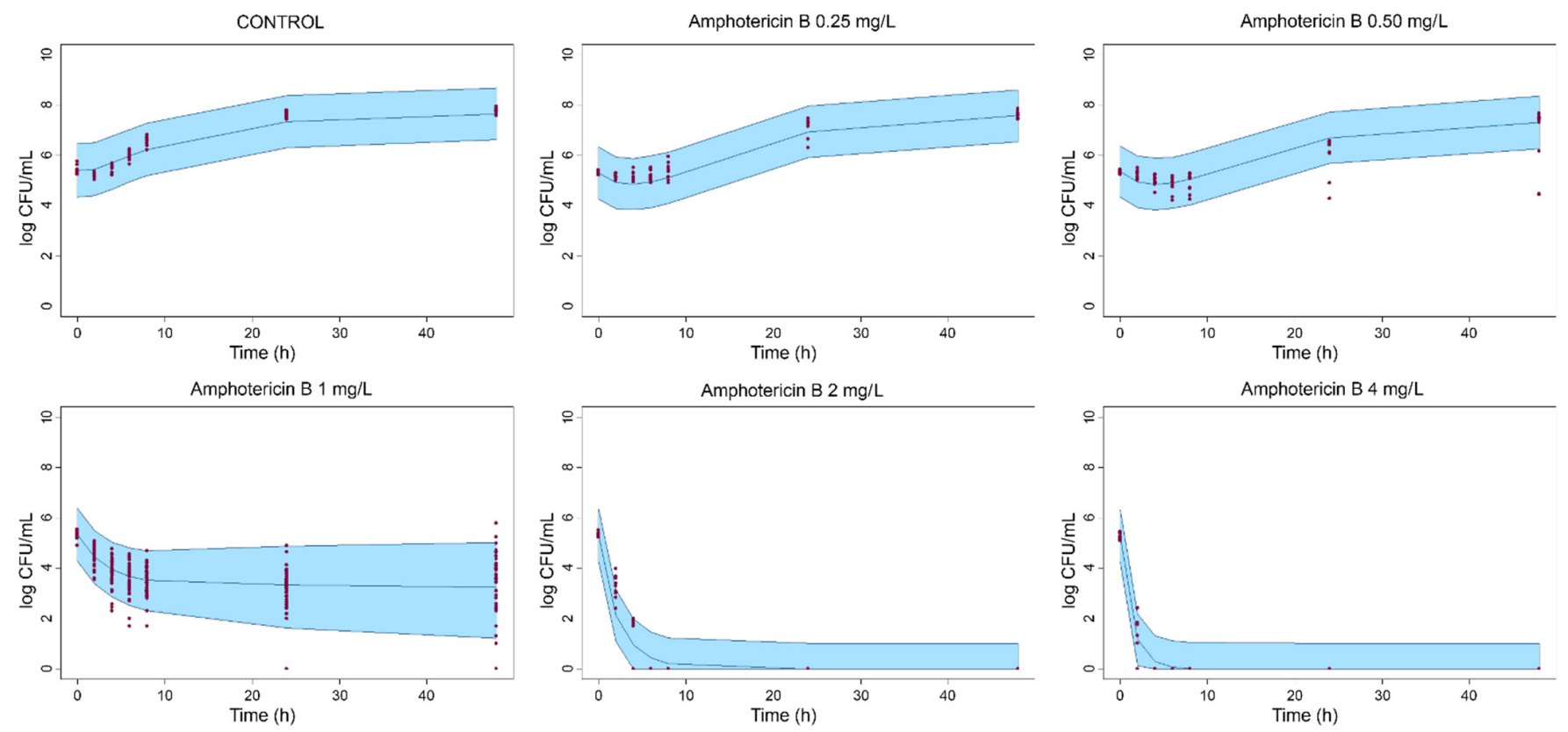

Figure 2. Visual predictive check (VPC) for the final model, with the observed fungal counts (full circles), the mean prediction (solid line) and 95\% model prediction interval (shaded area) of the simulations. 
Table 1. Parameter estimates (typical values and relative standard error -RSE- as CV \%) and bootstrap estimates (mean and $95 \% \mathrm{CI})$ of the PK/PD model.

\begin{tabular}{|c|c|c|c|}
\hline Parameter & Description & $\begin{array}{l}\text { Model Estimate and RSE } \\
\text { (CV\%) }\end{array}$ & $\begin{array}{l}\text { Bootstrap Estimate } \\
\text { (Mean and 95\% CI) }\end{array}$ \\
\hline $\mathrm{k}_{\text {growths }}\left(\mathrm{h}^{-1}\right)$ & $\begin{array}{l}\text { Fungal growth rate constant } \\
\text { of the } S \text { subpopulation }\end{array}$ & $0.111(3 \%)$ & $0.111(0.101-0.116)$ \\
\hline $\mathrm{k}_{\text {growthR }}\left(\mathrm{h}^{-1}\right)$ & $\begin{array}{c}\text { Fungal growth rate constant } \\
\text { of the R subpopulation }\end{array}$ & 0.01 (fixed) & - \\
\hline $\mathrm{k}_{\text {death }}\left(\mathrm{h}^{-1}\right)$ & Fungal death rate constant & 0.01 (fixed) & - \\
\hline $\mathrm{E}_{\max }\left(\mathrm{h}^{-1}\right)$ & $\begin{array}{c}\text { Maximum kill rate constant of } \\
\text { amphotericin B }\end{array}$ & $0.784(12 \%)$ & $0.795(0.635-1.04)$ \\
\hline $\mathrm{EC}_{50}(\mathrm{mg} / \mathrm{L})$ & $\begin{array}{l}\text { Concentration of } \\
\text { amphotericin B at which } 50 \% \\
\text { of the } E_{\max } \text { is achieved }\end{array}$ & $1.88(3 \%)$ & $1.89(1.78-2.05)$ \\
\hline $\mathrm{h}$ & $\begin{array}{l}\text { Hill factor that that modifies } \\
\text { the steepness of the slope and } \\
\text { smoothens the curve }\end{array}$ & 4 (fixed) & - \\
\hline$\alpha$ (control) & $\begin{array}{l}\text { Delay in fungal growth in the } \\
\text { absence of drug }\end{array}$ & $0.748(3 \%)$ & $0.754(0.664-0.882)$ \\
\hline$\alpha($ drug) & $\begin{array}{l}\text { Delay in fungal growth in the } \\
\text { presence of drug }\end{array}$ & $0.231(10 \%)$ & $0.233(0.193-0.274)$ \\
\hline $\mathrm{N}_{\max }(\log \mathrm{CFU} / \mathrm{mL})$ & Maximum fungal density & $7.66(1 \%)$ & $7.67(7.47-7.87)$ \\
\hline$\sigma(\log C F U / m L)$ & Residual error & $0.271(14 \%)$ & $0.270(0.190-0.327)$ \\
\hline$\pi_{1}(\% \mathrm{CV})$ & Occasion 1 & 0 (fixed) & - \\
\hline$\pi_{2}(\% \mathrm{CV})$ & Occasion 2 & $9.5(35 \%)$ & $9.22(2.45-15.34)$ \\
\hline$\pi_{3}(\% \mathrm{CV})$ & Occasion 3 & $18.4(24 \%)$ & $18.76(10.07-28.12)$ \\
\hline$\pi_{4}(\% \mathrm{CV})$ & Occasion 4 & $7.5(37 \%)$ & $7.13(2.75-13.19)$ \\
\hline
\end{tabular}

\subsection{Simulation of Standard Treatments Using Human PK Data}

The simulated total and unbound concentrations of amphotericin $B$ for typical intravenous dosing regimens of $0.6,1$ and $1.5 \mathrm{mg} / \mathrm{kg} /$ day and their expected activity on C. auris after a one-week treatment are shown in Figure 3. None of the simulated standard dosing scenarios showed successful activity against $C$. auris.

Additional simulations with MIC scenarios of $0.06,0.125,0.25$ and $0.5 \mathrm{mg} / \mathrm{L}$ (with $\mathrm{EC}_{50}$ of $0.12,0.24,0.47$ and $0.94 \mathrm{mg} / \mathrm{L}$, respectively) for a 1-week period are presented in Figure 4.

Simulations with the lowest dose, $0.6 \mathrm{mg} / \mathrm{kg} /$ day, showed that a fungistatic activity would be achieved at the 5th day of treatment for MIC values of amphotericin B of $0.06 \mathrm{mg} / \mathrm{L}$. The next simulated dose, $1 \mathrm{mg} / \mathrm{kg} /$ day, resulted in fungicidal activity from the second day onwards and fungistatic with the first administration. Finally, the highest dose of $1.5 \mathrm{mg} / \mathrm{kg} /$ day led to a fungicidal endpoint immediately after the first administration. Additionally, for an MIC of $0.125 \mathrm{mg} / \mathrm{L}$ a fungistatic effect would be achieved at the $3 \mathrm{rd}$ day, and fungicidal at the 5th day at this highest dose level. 

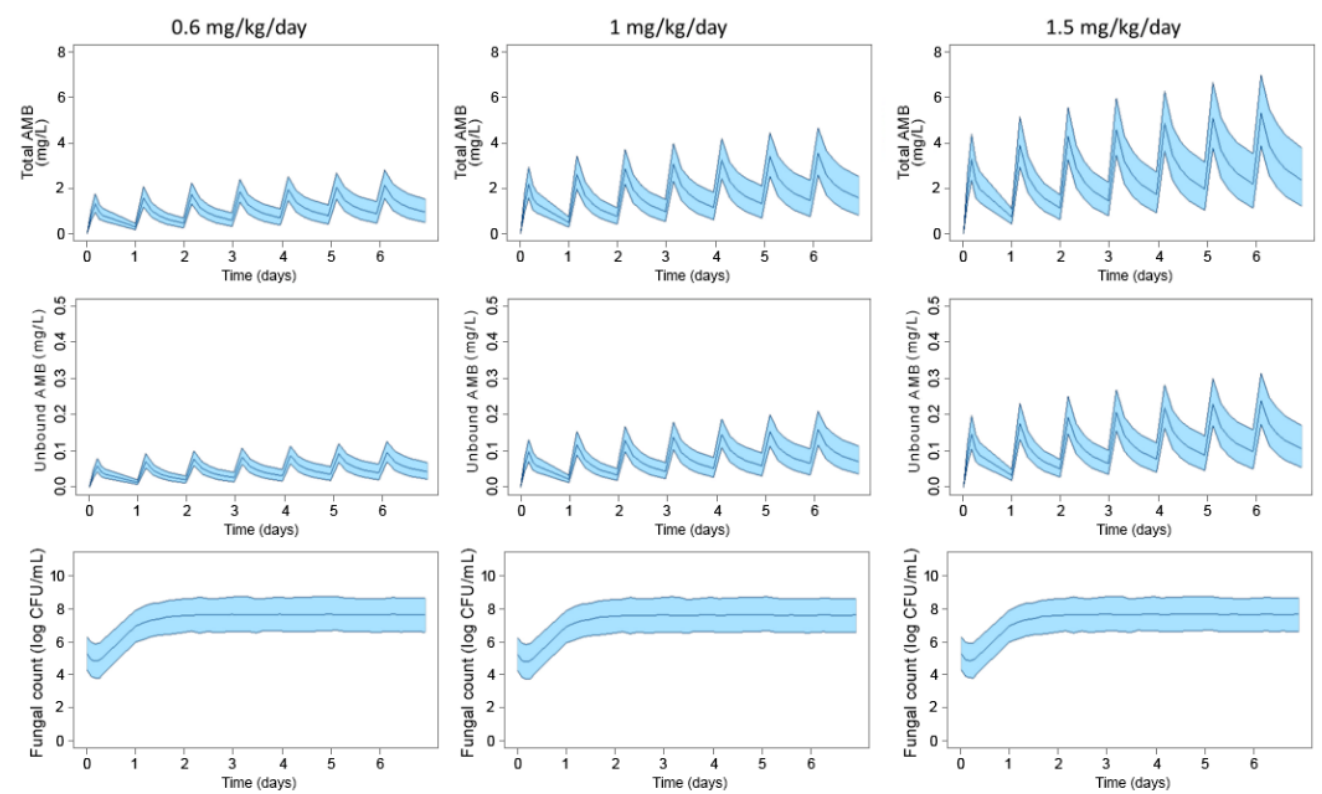

(b)

Figure 3. Predicted total (top row) and unbound (mid row) plasma concentrations of amphotericin $\mathrm{B}$ (D-AMB) and the effect on fungal burden (bottom row) for the treatment of $0.6 \mathrm{mg} / \mathrm{kg} / \mathrm{day}(\mathbf{a})$, $1 \mathrm{mg} / \mathrm{kg} /$ day (b) and $1.5 \mathrm{mg} / \mathrm{kg} /$ day (c) of amphotericin B. The mean (solid line) and 95\% prediction interval (coloured space) are represented.

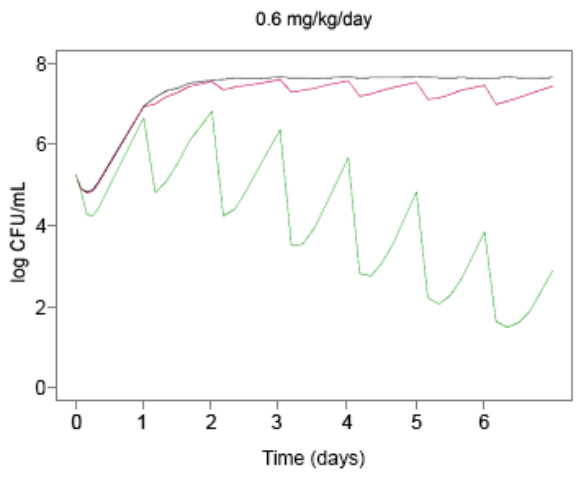

(a)

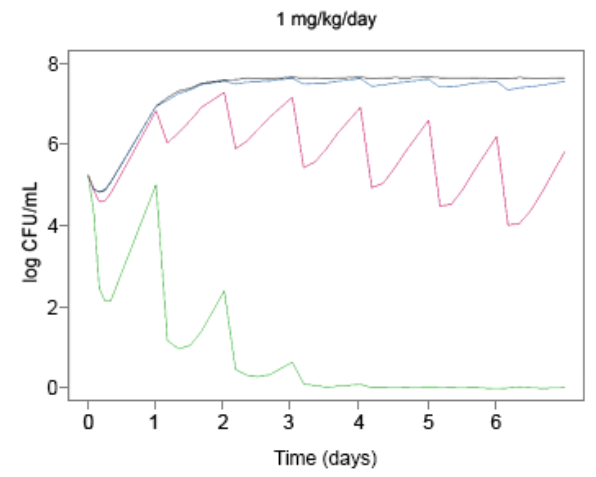

(b)

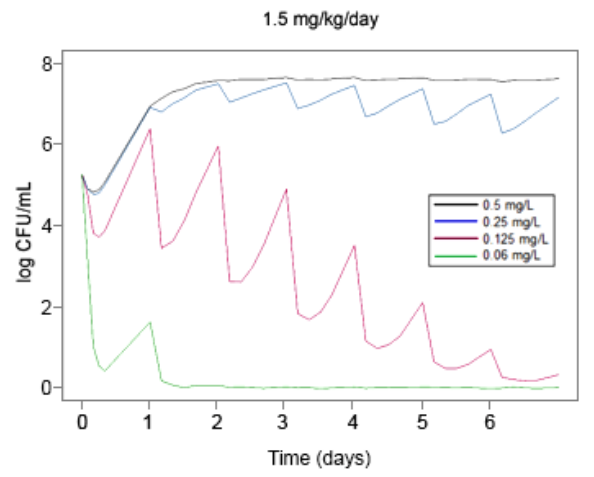

(c)

Figure 4. Simulations of the effect of amphotericin B on fungal burden by MIC and by dosing regimens of $0.6 \mathrm{mg} / \mathrm{kg} / \mathrm{day}$ (a), $1 \mathrm{mg} / \mathrm{kg} /$ day (b) and $1.5 \mathrm{mg} / \mathrm{kg} /$ day (c). Black line: MIC of $0.5 \mathrm{mg} / \mathrm{L}$; blue line: MIC of $0.25 \mathrm{mg} / \mathrm{L}$; purple line: MIC of $0.125 \mathrm{mg} / \mathrm{L}$; green line: MIC of $0.06 \mathrm{mg} / \mathrm{L}$.

\section{Discussion}

C. auris is an emergent fungal pathogen with reduced susceptibility to first-line antifungal agents. Amphotericin B is an antifungal drug with proven efficacy against invasive candidiasis and a low resistance-rate despite more than six decades of use; a correct and thorough knowledge about the activity of this drug against $C$. auris is necessary. To date, most susceptibility studies on this pathogen have focused on the determination of the MIC. The MIC is the standard PD parameter used as a marker of fungal susceptibility and antimicrobial efficacy, yet it possesses some limitations. The antimicrobial activity of drugs is a dynamic process, while MIC is a threshold value. Concentrations below or above the MIC are ignored and thus, a more precise and quantitative information about the concentration-effect profile of the drug is often missing [29]. It is also noteworthy that even for the same microbial species, same MIC values among different isolates can result 
in different killing kinetics [24]. Thus, studies that characterize the antimicrobial activity beyond the measurement of MIC are needed. In vitro time-kill curves allow obtaining more information about the effect of different drug concentrations on microbial population over a time period. In combination with PK/PD M\&S, these time-kill curve experiments provide an interesting tool to predict and simulate untested scenarios that may help in decision-making and design of further studies.

As determined for other species of Candida $[30,31]$, in the present study amphotericin $B$ showed concentration-dependent activity against $C$. auris in T-K experiments. Fungicidal activity was achieved at concentrations $\geq 2 \mathrm{mg} / \mathrm{L}$ and in less than $2 \mathrm{~h}$. These results are in agreement with the only published work based on T-K curve methodology against $\mathrm{C}$. auris, in which MIC values of amphotericin B were also $1 \mathrm{mg} / \mathrm{L}$ [16]. Additionally, this killing kinetic pattern has also been described for other species of Candida that have been regarded as resistant to amphotericin B treatment [31,32].

Few PK/PD models are available for antifungal agents [19-21]. To our knowledge, the present study is the first work that used a semi-mechanistic approach to model the antifungal activity of amphotericin B against $C$. auris. The static T-K experiments performed showed fungal regrowth or a biphasic trend, and therefore, a semi-mechanistic model that included two fungal subpopulations with different susceptibility to the drug best captured this behaviour. This approach has been extensively applied to successfully model antibiotic activity $[25,33]$. In the model of the present study, the emergence of resistance is triggered by a high microbial count, with the susceptible population switching to a resistant one, a process described by a first-order rate constant that also accounted for the self-limiting growth rate, as it has been previously proposed by other authors $[25,34]$. The model best fitted the data when a different growth rate constant for the resistant subpopulation was defined $\left(\mathrm{k}_{\text {growthR }}\right)$; this parameter was estimated to be 10 times lower than the growth rate constant for the susceptible subpopulation ( $\mathrm{k}_{\text {growths }}$ ), which is in agreement with the 'fitness cost' observed in some species of Candida when they develop resistance mechanisms [35]. Moreover, phenotypic switching during treatment with amphotericin $B$ has been described for Candida lusitaniae [36], a closely related species of $C$. auris. Nevertheless, the main goal of model building was to accurately describe the antimicrobial activity and perform simulations rather than to provide insight into resistance mechanisms, for which specific microbiological and molecular procedures would be needed. On the other hand, the lack of similar PK/PD models reports for $C$. auris or amphotericin B in the literature has precluded comparisons.

A three-compartment model for amphotericin B deoxycholate [26] was implemented for the simulation of plasma concentrations of the drug in human patients for dosing regimens of $0.6,1$ and $1.5 \mathrm{mg} / \mathrm{kg} /$ day. The latter is more commonly used for invasive aspergillosis rather than for candidemia [37], but we considered this dosing schedule for simulation purposes too due to the low susceptibility profile of $C$. auris and the concentrationdependent PD of amphotericin B shown in the present study, in concordance with other in vitro and in vivo results $[16,38]$. Higher doses were not considered due to the toxicity of the drug. Amphotericin B, as many antifungal agents, is highly bounded to plasma proteins, around $95 \%$ at clinically achievable concentrations [27], and this feature was taken into account in the PK/PD simulations.

With regard to the different pharmaceutical formulations available, liposomal amphotericin $\mathrm{B}$ (L-AMB) is the current first choice due to its improved safety profile and comparable efficacy to conventional amphotericin B deoxycholate. However, the cost can be too high for healthcare systems in developing countries, which makes the conventional formulation still relevant and listed as essential drug [39]. On the other hand, it is still not clear which fraction of the total plasma concentration of L-AMB is active, as protein binding is not applicable for this formulation [40], which makes the bridging between in vitro experiments and in vivo simulations harder to perform. Therefore, the simulations were carried out for the deoxycholate formulation. Nevertheless, studies in animal models of invasive candidiasis and clinical trials have shown similar efficacy for both formula- 
tions [40]. This may reflect a comparable exposition of the fungal population to free drug and therefore conclusions driven by PK/PD simulations may be applicable for L-AMB too. In fact, EUCAST susceptibility breakpoints are based on adult standard dosages of both formulations [41].

As previously mentioned, an approach solely based on the MIC of antimicrobials provides limited information. Conversely, PD parameters derived from the analysis of T-K curves, such as $\mathrm{E}_{\max }$ and $\mathrm{EC}_{50}$, give more detailed information on the activity of the drug. However, obtaining these data in the clinical setting is time-consuming, laborious and usually not feasible. This drawback can be overcome by employing mathematical relationship between the $\mathrm{MIC}$ and $\mathrm{EC}_{50}$, as it has been demonstrated in the present study, since it is possible to link the results of the PK/PD modelling and simulation of T-K curves with the MIC of the drug [28].

Simulations of standard dosages of amphotericin B deoxycholate pointed out that the treatment would not be effective against the clinical isolates tested in this study. Additionally, other possible treatment outcomes were tested by simulating different susceptibility scenarios, with MICs below $1 \mathrm{mg} / \mathrm{L}$. Standard treatments of 0.6 and $1 \mathrm{mg} / \mathrm{kg} /$ day would only be effective against $C$. auris isolates for an MIC of $0.06 \mathrm{mg} / \mathrm{L}$. However, a higher dosage of $1.5 \mathrm{mg} / \mathrm{kg} /$ day would also be effective for an MIC up to $0.125 \mathrm{mg} / \mathrm{L}$. Therefore, contrary to expectations [7], susceptibility breakpoint of amphotericin B for C. auris might be lower than $1 \mathrm{mg} / \mathrm{L}$. Similar threshold values for amphotericin B have been reported for other species of Candida and filamentous fungi, such as Aspergillus. In a murine model of invasive candidiasis caused by Candida krusei, a daily dose of $1 \mathrm{mg} / \mathrm{kg}$ of amphotericin $\mathrm{B}$ was effective in reducing the kidney fungal burden when the MIC of the drug was of $0.125 \mathrm{mg} / \mathrm{L}$, but ineffective when MIC was of $0.5 \mathrm{mg} / \mathrm{L}$ [42]. In another murine model study, doses of $1.5 \mathrm{mg} / \mathrm{kg} /$ day of amphotericin B resulted in a 15-day survival percentage of $>50 \%$ for Candida glabrata and $<25 \%$ for Candida tropicalis, the MIC being $1 \mathrm{mg} / \mathrm{L}$ for both species [43]. In an in vitro dynamic system that mimicked human PK of unbound amphotericin B against Aspergillus, those species considered resistant to amphotericin B had a probability of target attainment (PTA) of $0 \%$ when the MIC was $1 \mathrm{mg} / \mathrm{L}$; for a PTA of $80 \%$ an MIC of $0.25 \mathrm{mg} / \mathrm{L}$ was needed [44]. On the other hand, a work that analysed the effect of antifungal drugs against $C$. auris infection in a murine model of invasive candidiasis concluded that the MIC cut-off for amphotericin B was $1.5 \mathrm{mg} / \mathrm{L}$ [38]. However, variability between strains was high and the $50 \%$ effective dose $\left(\mathrm{ED}_{50}\right)$ was as high as $5 \mathrm{mg} / \mathrm{kg} /$ day, a dose that can be lethal [45].

The results obtained in this study should be cautiously interpreted, as in vitro-in vivo correlation studies for amphotericin B against $C$. auris are lacking. Even though T-K curve methodology is a more complex technique that provides further information than MIC determination, it is still an in vitro approximation to the much more complex in vivo reality. Factors such as host immunity status and drug tissue distribution are overlooked, whereas fungal burden may be overestimated, as growth rate is much faster in the rich environment of the microbiological broth culture than in the human infection sites [46]. Nevertheless, the developed model and simulation results may help in the design of future preclinical and clinical studies, providing a useful tool for dosing regimen selection. It would also be of interest to further confirm in a murine candidiasis model if the MIC of $1 \mathrm{mg} / \mathrm{L}$ is linked to treatment failure.

\section{Conclusions}

In conclusion, the developed PK/PD model was able to properly characterize the antifungal activity of amphotericin $B$ against $C$. auris. The simulations highlighted that an MIC of $1 \mathrm{mg} / \mathrm{L}$ would be linked to treatment failure and in consequence, the amphotericin $\mathrm{B}$ resistance rate in this fungal species may be higher than previously reported [1]. These results may be extrapolated to C. auris clinical isolates with similar $\mathrm{EC}_{50} / \mathrm{MIC}$ ratio. Nevertheless, further studies are needed to fully characterize the susceptibility profile of $C$. auris and optimize antifungal therapy. 
Author Contributions: Conceptualization, U.C., N.J., E.E. and G.Q.; methodology, U.C., E.E., J.P., V.V., S.S. and N.J.; software, U.C., V.V., S.S. and N.J.; validation, U.C. and V.V.; formal analysis, U.C. and N.J.; investigation, U.C., S.S., G.Q. and N.J.; resources, N.J., G.Q. and E.E.; data curation, U.C.; writing—original draft preparation, U.C., V.V. and N.J.; writing-review and editing, U.C., E.E., G.Q., V.V., S.S. and N.J.; visualization, U.C., E.E., G.Q., J.P., V.V., S.S. and N.J.; supervision, N.J. and G.Q.; project administration, N.J., E.E., J.P. and G.Q.; and funding acquisition, J.P., G.Q., E.E. and N.J. All authors have read and agreed to the published version of the manuscript.

Funding: This research was funded by Consejería de Educación, Universidades e Investigación of Gobierno Vasco-Eusko Jaurlaritza, GIC15/78 IT-990-16 and by FIS, Spain, PI17/01538. U.C. was funded by a Ph.D. grant from the University of the Basque Country, PIF 17/266.

Institutional Review Board Statement: Not applicable.

Informed Consent Statement: Not applicable.

Conflicts of Interest: The authors declare no conflict of interest.

\section{References}

1. Chowdhary, A.; Sharma, C.; Meis, J.F. Candida auris: A rapidly emerging cause of hospital-acquired multidrug-resistant fungal infections globally. PLoS Pathog. 2017, 13, e1006290. [CrossRef] [PubMed]

2. Quindós, G.; Marcos-Arias, C.; San-Millán, R.; Mateo, E.; Eraso, E. The continuous changes in the aetiology and epidemiology of invasive candidiasis: From familiar Candida albicans to multiresistant Candida auris. Int. Microbiol. 2018, 21, 107-119. [CrossRef]

3. Sekyere, J.O. Candida auris: A systematic review and meta-analysis of current updates on an emerging multidrug-resistant pathogen. Microbiology 2018, 7, e00578. [CrossRef] [PubMed]

4. Pemán, J.; Ruiz-Gaitán, A.; García-Vidal, C.; Salavert, M.; Ramírez, P.; Puchades, F.; García-Hita, M.; Alastruey-Izquierdo, A.; Quindós, G. Fungal co-infection in COVID-19 patients: Should we be concerned? Rev. Iberoam. Micol. 2020, 37, 41-46. [CrossRef]

5. Arendrup, M.C.; Prakash, A.; Meletiadis, J.; Sharma, C.; Chowdhary, A. Comparison of EUCAST and CLSI reference microdilution MICs of eight antifungal compounds for Candida auris and associated tentative epidemiological cutoff values. Antimicrob. Agents Chemother. 2017, 61, e00485-17. [CrossRef]

6. Chaabane, F.; Graf, A.; Jequier, L.; Coste, A.T. Review on Antifungal Resistance Mechanisms in the Emerging Pathogen Candida auris. Front. Microbiol. 2019, 10, 2788. [CrossRef]

7. Lockhart, S.R. Candida auris and multidrug resistance: Defining the new normal. Fungal Genet. Biol. 2019, 131, 103243. [CrossRef]

8. Chowdhary, A.; Prakash, A.; Sharma, C.; Kordalewska, M.; Kumar, A.; Sarma, S.; Tarai, B.; Singh, A.; Upadhyaya, G.; Upadhyay, S.; et al. A multicentre study of antifungal susceptibility patterns among 350 Candida auris isolates (2009-2017) in India: Role of the ERG11 and FKS1 genes in azole and echinocandin resistance. J. Antimicrob. Chemother. 2018, 73, 891-899. [CrossRef]

9. Kenters, N.; Kiernan, M.; Chowdhary, A.; Denning, D.W.; Pemán, J.; Saris, K.; Schelenz, S.; Tartari, E.; Widmer, A.; Meis, J.F.; et al. Control of Candida auris in healthcare institutions: Outcome of an International Society for Antimicrobial Chemotherapy expert meeting. Int. J. Antimicrob. Agents 2019, 54, 400-406. [CrossRef]

10. Biagi, M.J.; Wiederhold, N.P.; Gibas, C.; Wickes, B.; Lozano, V.; Bleasdale, S.C.; Danziger, L. Development of High-Level Echinocandin Resistance in a Patient with Recurrent Candida auris Candidemia Secondary to Chronic Candiduria. Open Forum Infect. Dis. 2019, 6, ofz262. [CrossRef] [PubMed]

11. Shin, J.H.; Kim, M.-N.; Jang, S.J.; Ju, M.Y.; Kim, S.H.; Shin, M.G.; Suh, S.P.; Ryang, D.W. Detection of Amphotericin B Resistance in Candida haemulonii and Closely Related Species by Use of the Etest, Vitek-2 Yeast Susceptibility System, and CLSI and EUCAST Broth Microdilution Methods. J. Clin. Microbiol. 2012, 50, 1852-1855. [CrossRef]

12. Morales, S.; Giraldo, C.M.P.; Garzón, A.C.; Martínez, H.P.; Rodríguez, G.J.; Moreno, C.A.A.; Rodriguez, J.Y. Invasive Infections with Multidrug-Resistant Yeast Candida auris, Colombia. Emerg. Infect. Dis. 2017, 23, 162-164. [CrossRef] [PubMed]

13. Chowdhary, A.; Sharma, C.; Duggal, S.; Agarwal, K.; Prakash, A.; Singh, P.K.; Jain, S.; Kathuria, S.; Randhawa, H.S.; Hagen, F.; et al. New Clonal Strain of Candida auris, Delhi, India. Emerg. Infect. Dis. 2013, 19, 1670-1673. [CrossRef]

14. Calvo, B.; Melo, A.S.A.; Perozo-Mena, A.; Hernandez, M.; Francisco, E.C.; Hagen, F.; Meis, J.F.; Colombo, A.L. First report of Candida auris in America: Clinical and microbiological aspects of 18 episodes of candidemia. J. Infect. 2016, 73, 369-374. [CrossRef]

15. Schelenz, S.; Hagen, F.; Rhodes, J.L.; Abdolrasouli, A.; Chowdhary, A.; Hall, A.; Ryan, L.; Shackleton, J.; Trimlett, R.; Meis, J.F.; et al. First hospital outbreak of the globally emerging Candida auris in a European hospital. Antimicrob. Resist. Infect. Control. 2016, 5, 1-7. [CrossRef]

16. Dudiuk, C.; Berrio, I.; Leonardelli, F.; Morales-Lopez, S.; Theill, L.; Macedo, D.; Rodriguez, J.Y.; Salcedo, S.; Marin, A.; Gamarra, S.; et al. Antifungal activity and killing kinetics of anidulafungin, caspofungin and amphotericin B against Candida auris. J. Antimicrob. Chemother. 2019, 74, 2295-2302. [CrossRef] [PubMed]

17. Spivak, E.S.; Hanson, K.E. Candida auris: An Emerging Fungal Pathogen. J. Clin. Microbiol. 2018, 56, e01588-17. [CrossRef] [PubMed] 
18. Alastruey-Izquierdo, A.; Asensio, A.; Besoli, A.; Calabuig, E.; Fernández-Ruiz, M.; Garcia-Vidal, C.; Gasch, O.; Guinea, J.; Martín-Gomez, M.T.; Paño, J.R. GEMICOMED/GEIRAS-SEIMC recommendations for the management of Candida auris infection and colonization. Rev. Iberoam. Micol. 2019, 36, 109-114. [CrossRef]

19. Venisse, N.; Grégoire, N.; Marliat, M.; Couet, W. Mechanism-Based Pharmacokinetic-Pharmacodynamic Models of In Vitro Fungistatic and Fungicidal Effects against Candida albicans. Antimicrob. Agents Chemother. 2008, 52, 937-943. [CrossRef] [PubMed]

20. Li, Y.; Nguyen, M.H.; Cheng, S.; Schmidt, S.; Zhong, L.; Derendorf, H.; Clancy, C.J. A pharmacokinetic/pharmacodynamic mathematical model accurately describes the activity of voriconazole against Candida spp. in vitro. Int. J. Antimicrob. Agents 2008, 31, 369-374. [CrossRef]

21. Gil-Alonso, S.; Jauregizar, N.; Ortega, I.; Eraso, E.; Suarez, E.; Quindós, G. In vitro pharmacodynamic modelling of anidulafungin against Candida spp. Int. J. Antimicrob. Agents 2016, 47, 178-183. [CrossRef]

22. Ruiz-Gaitán, A.; Moret, A.M.; Tasias-Pitarch, M.; Aleixandre-López, A.I.; Morel, H.M.; Calabuig, E.; Salavert-Lletí, M.; Ramírez, P.; López-Hontangas, J.L.; Hagen, F.; et al. An outbreak due to Candida auris with prolonged colonisation and candidaemia in a tertiary care European hospital. Mycoses 2018, 61, 498-505. [CrossRef]

23. EUCAST. The European Committee for Antimicrobial Susceptibility Testing. Method for the Determination of Broth Dilution Minimum Inhibitory Concentrations of Antifungal Agents for Yeasts. EUCAST Definitive Document E.def 7.3.2. 2020. Available online: https://www.eucast.org/fileadmin/src/media/PDFs/EUCAST_files/AFST/Files/EUCAST_E_Def_7.3.2_Yeast_testing_ definitive_revised_2020.pdf (accessed on 8 March 2021).

24. Gil-Alonso, S.; Jauregizar, N.; Canton, E.; Eraso, E.; Quindos, G. In vitro fungicidal activities of anidulafungin, caspofungin, and micafungin against Candida glabrata, Candida bracarensis, and Candida nivariensis evaluated by time-kill studies. Antimicrob. Agents Chemother. 2015, 59, 3615-3618. [CrossRef]

25. Nielsen, E.I.; Friberg, L.E. Pharmacokinetic-Pharmacodynamic Modeling of Antibacterial Drugs. Pharmacol. Rev. 2013, 65, 1053-1090. [CrossRef]

26. Bekersky, I.; Fielding, R.; Dressler, D.E.; Lee, J.W.; Buell, D.N.; Walsh, T.J. Pharmacokinetics, Excretion, and Mass Balance of Liposomal Amphotericin B (AmBisome) and Amphotericin B Deoxycholate in Humans. Antimicrob. Agents Chemother. 2002, 46, 828-833. [CrossRef] [PubMed]

27. Bekersky, I.; Fielding, R.; Dressler, D.E.; Lee, J.W.; Buell, D.N.; Walsh, T.J. Plasma Protein Binding of Amphotericin B and Pharmacokinetics of Bound versus Unbound Amphotericin B after Administration of Intravenous Liposomal Amphotericin B (AmBisome) and Amphotericin B Deoxycholate. Antimicrob. Agents Chemother. 2002, 46, 834-840. [CrossRef]

28. Schmidt, S.; Schuck, E.; Kumar, V.; Burkhardt, O.; Derendorf, H. Integration of pharmacokinetic/pharmacodynamic modeling and simulation in the development of new anti-infective agents-Minimum inhibitory concentration versus time-kill curves. Expert Opin. Drug Discov. 2007, 2, 849-860. [CrossRef]

29. Mueller, M.; de la Peña, A.; Derendorf, H. Issues in Pharmacokinetics and Pharmacodynamics of Anti-Infective Agents: Kill Curves versus MIC. Antimicrob. Agents Chemother. 2004, 48, 369-377. [CrossRef] [PubMed]

30. Klepser, M.E.; Wolfe, E.J.; Jones, R.N.; Nightingale, C.H.; Pfaller, M.A. Antifungal pharmacodynamic characteristics of fluconazole and amphotericin B tested against Candida albicans. Antimicrob. Agents Chemother. 1997, 41, 1392-1395. [CrossRef] [PubMed]

31. Cantón, E.; Pemán, J.; Gobernado, M.; Viudes, A.; Espinel-Ingroff, A. Patterns of Amphotericin B Killing Kinetics against Seven Candida Species. Antimicrob. Agents Chemother. 2004, 48, 2477-2482. [CrossRef] [PubMed]

32. Canton, E.; Peman, J.; Sastre, M.; Romero, M.; Espinel-Ingroff, A. Killing kinetics of caspofungin, micafungin, and ampho-tericin B against Candida guilliermondii. Antimicrob. Agents Chemother. 2006, 50, 2829-2832. [CrossRef]

33. Brill, M.; Kristoffersson, A.; Zhao, C.; Nielsen, E.; Friberg, L. Semi-mechanistic pharmacokinetic-pharmacodynamic modelling of antibiotic drug combinations. Clin. Microbiol. Infect. 2018, 24, 697-706. [CrossRef]

34. Nielsen, E.I.; Viberg, A.; Lowdin, E.; Cars, O.; Karlsson, M.O.; Sandstrom, M. Semimechanistic pharmacokinet-ic/pharmacodynamic model for assessment of activity of antibacterial agents from time-kill curve experiments. Antimicrob. Agents Chemother. 2007, 51, 128-136. [CrossRef]

35. Sasse, C.; Dunkel, N.; Schäfer, T.; Schneider, S.; Dierolf, F.; Ohlsen, K.; Morschhäuser, J. The stepwise acquisition of fluconazole resistance mutations causes a gradual loss of fitness inCandida albicans. Mol. Microbiol. 2012, 86, 539-556. [CrossRef]

36. Asner, S.; Giulieri, S.; Diezi, M.; Marchetti, O.; Sanglard, D. Acquired Multidrug Antifungal Resistance in Candida lusitaniae During Therapy. Open Forum Infect. Dis. 2015, 59, 7715-7722. [CrossRef]

37. European Committee on Antimicrobial Susceptibility Testing. Amphotericin B: Rationale for the Clinical Breakpoints, Version 2.0. 2020. Available online: http:/ /www.eucast.org (accessed on 25 February 2021).

38. Lepak, A.J.; Zhao, M.; Berkow, E.L.; Lockhart, S.R.; Andes, D.R. Pharmacodynamic Optimization for Treatment of Invasive Candida auris Infection. Antimicrob. Agents Chemother. 2017, 61, 00791-17. [CrossRef]

39. World Health Organization Model List of Essential Medicines, 21st List, 2019. World Health Organization: Geneva, Switzerland, 2019. Available online: https://www.who.int/medicines/publications/essentialmedicines/en/ (accessed on 8 March 2021).

40. Groll, A.H.; Rijnders, B.; Walsh, T.J.; Adler-Moore, J.; Lewis, R.E.; Brüggemann, R.J.M. Clinical Pharmacokinetics, Pharmacodynamics, Safety and Efficacy of Liposomal Amphotericin B. Clin. Infect. Dis. 2019, 68, S260-S274. [CrossRef] 
41. Arendrup, M.; Friberg, N.; Mares, M.; Kahlmeter, G.; Meletiadis, J.; Guinea, J.; Andersen, C.; Arikan-Akdagli, S.; Barchiesi, F.; Chryssanthou, E.; et al. How to interpret MICs of antifungal compounds according to the revised clinical breakpoints v. 10.0 European committee on antimicrobial susceptibility testing (EUCAST). Clin. Microbiol. Infect. 2020, 26, 1464-1472. [CrossRef]

42. Kardos, T.; Kovács, R.; Kardos, G.; Varga, I.; Bozó, A.; Tóth, Z.; Nagy, F.; Majoros, L. Poor in vivo efficacy of caspofungin, micafungin and amphotericin B against wild-type Candida krusei clinical isolates does not correlate with in vitro susceptibility results. J. Chemother. 2018, 30, 233-239. [CrossRef]

43. Mariné, M.; Espada, R.; Torrado, J.; Pastor, F.J.; Guarro, J. Efficacy of a new formulation of amphotericin B in murine disseminated infections by Candida glabrata or Candida tropicalis. Int. J. Antimicrob. Agents 2009, 34, 566-569. [CrossRef]

44. Elefanti, A.; Mouton, J.W.; Verweij, P.E.; Zerva, L.; Meletiadis, J. Susceptibility Breakpoints for Amphotericin B and Aspergillus Species in anIn VitroPharmacokinetic-Pharmacodynamic Model Simulating Free-Drug Concentrations in Human Serum. Antimicrob. Agents Chemother. 2014, 58, 2356-2362. [CrossRef]

45. Mohr, J.F.; Hall, A.C.; Ericsson, C.D.; Ostrosky-Zeichner, L. Fatal Amphotericin B Overdose Due to Administration of Nonlipid Formulation Instead of Lipid Formulation. Pharmacother. J. Hum. Pharmacol. Drug Ther. 2005, 25, 426-428. [CrossRef]

46. De la Peña, A.; Gräbe, A.; Rand, K.H.; Rehak, E.; Gross, J.; Thyroff-Friesinger, U.; Müller, M.; Derendorf, H. PK-PD modelling of the effect of cefaclor on four different bacterial strains. Int. J. Antimicrob. Agents 2004, 23, 218-225. [CrossRef] 